\title{
Pemberian Mol Nasi Basi dengan Mol Limbah Buah Pepaya dengan Dosis yang Berbeda Terhadap Pertumbuhan dan Produksi Tanaman Terong (Solanum Melogena L.)
}

\author{
Amir $\mathbf{M}^{1 *}$, Adel Mariana ${ }^{2}$, Abd Jamal ${ }^{3}$, Harli A. Karim ${ }^{4}$ \\ ${ }^{1}$ Program Studi Agroekoteknologi, Fakultas Pertanian dan Kehutanan, Universitas Sulawesi Barat \\ 2, 3,4 Program Studi Agroteknologi, Fakultas Pertanian, Universitas Al Asyariah Mandar
}

Email: amir@unsulbar. ac.id

\begin{abstract}
Terong merupakan komoditas sayuran hortikultura yang digemari masyarakat dan terong masih memberikan peluang yang cukup baik peluang, pasar yang cukup baik terutama untuk memenuhi permintaan pasar, kemudian secara berangsur-angsur tanaman terung mulai dibudidayakan karena buahnya dapat digunakan untuk bahan makanan sayuran. Penilitian ini bertujuan untuk mengetahui Pemberian Mol Limbah Buah Pepaya dengan Dosis yang berbeda Terhadap Pertumbuhan dan produksi Tanaman Terong ungu. Penilitian ini dilaksanakan, di lahan Fakultas Pertanian Universitas Al-Asy'arih Mandar, Kelurahan Madatte, Kecamatan Polewali, Kabupaten Polewali Mandar. Berlangsung dari bulan Agustus sampai bulan Oktober 2018 Penilitian ini dilaksanakan dalam bentuk rancangan acak kelompok (RAK). Pemberian Mol Limbah Buah Pepaya dengan dosis yang berbeda dengan 1 faktor yang terdiri dari 9 tarap. Hasil penilitian menujukan bahwa Pemberian Mol Nasi Basi 20 ml/liter air + Mol Limbah Buah Pepaya dengan dosis 20 ml/litir air (M8) memberikan pengaruh terbaik tinggi tanaman, diameter batang, jumlah daun, jumlah buah dan bobot buah.
\end{abstract}

Keywords : Terong; Mol Nasi Basi; MoL Limbah Buah

\section{Pendahuluan}

Terong (Solanum melongena L.) merupakan salah satu produk tanaman hortikultura yang sudah banyak tersebar di Indonesia. Tanaman terong berasal dari Sri Lanka dan India. Buahnya mempunyai beragam warna yakni ungu, hijau, dan putih. Di Indonesia, terong sering disajikan dalam berbagai hidangan, mulai dari sayuran berkuah hingga lalapan. Sama seperti sayuran-sayuran lainnya, terong menawarkan berbagai manfaat kesehatan yang baikbagi tubuh. (Joko Prianto, 2016).

Manfaat terong bagi kesehatan tubuh adalah terdapat pada kandungan nutrisi nutrisinya. Rukmana, (2013). menyatakan bahwa terong kaya vitamin C, K, B6,vitamin, magnesium, fosfor, tembaga, serat, asam folat, kalium, dan mangan. Selain itu terong sedikit sekali mengandung kolesterol atau lemak jenuh. Terong juga mengandung banyak khasiat bagi kesehatan karena dapat menurunkan kolesterol darah, mengandung zat anti kanker, menjadi alat kontrasepsi, (Faisal M.S.2012). Potensi pasar terong juga dapat dilihat dari segi harga yang terjangkau oleh seluruh lapisan masyarakat sehingga membuka peluang yang lebih besar terhadap serapan pasar dan petani. Oleh karena itu, permintaan komoditas terong akan terus meningkat seiring dengan pertambahan jumlah penduduk dan semakin meningkatnya kesadaran masyarakat terhadap kesehatan. Permintaan terhadap terong terus meningkat sejalan dengan pertambahan penduduk yang diikuti dengan meningkatnya kesadaran akan manfaat sayur-sayuran dalam memenuhi gizi keluarga, sehingga produksi terong perlu terus ditingkatkan (Jumini, 2009). Hal tersebut sesuai dengan data Kementrian Pertanian Republik Indonesia (2017), dimana produksi terong pada tahun
2012 mencapai 518,787 ton, pada tahun 2013 mencapai 545,646 ton dan pada tahun 2014 mencapai 557,040 ton. Upaya untuk meningkatkan produksi terong salah satunya dapat dilakukan dengan penanaman varietas terong yang unggul.

Meskipun produksi terong nasional tiap tahun cenderung meningkat namun produksi terung di Indonesia masih rendah dan hanya menyumbang $1 \%$ dari kebutuhan dunia (Simatupang, 2010). Hal ini antara lain disebabkan oleh luas lahan budidaya terong yang masih sedikit dan bentuk kultur budidayanya masih bersifat sampingan dan belum intensif. Dalam hal ini juga di pengaruhi penggunaan pupuk yang tidak tepat dan pemakian pupuk kimia yang terus - menerus sehingga mengakibatkan turunya tingkat kesuburahan Apabila residu tidak terurai maka akan menjadi racun bagi tanah, tanah akan menjadi sakit oleh karna itu. Penggunaan pupuk organic sangat dibutuhkan seperti Pemberian Mikrorganisme Lokal (Mol) agar keseimbangan unsur hara dapat seimbang serta menghasilkan produksi yang optimal. lahan yang menyebabkan banyaknya residu yang melebih daya dukung lingkungan. Penggunaan pupuk kimia secara terus menerus dapat merusak sifat fisik, biologi tanah, dan menyebabkan degradasi lahan pertanian sehingga efisiensinya menurun akibat sebagian besar pupuk hilang melalui pencucuian, fiksasi atau penguapan dan hargax relatip mahal (Musnawar 2007).

Dengan penggunaan Mikroorganisme Lokal (Mol) dapat menambah unsur hara makro,mikro, dan mengandung mikroorganisme yang berpontensi sebagai perombak bahan organik perangsang pertumbuhan, dan agen pengendalian hama dan penyakit pada tanaman (Handayani dkk,.2015). Mikrorganisme Lokal (Mol) nasi 
basi adalah sebagai larutan yang mengandung mikroba yang bisa membantu keterersedian unsur hara pada tanaman agar bisa diserap oleh tanaman. (Hermawati 2009)

Berdasarkan hal tersebut maka dilaksanakan penelitian tentang Pemberiaan Mol Nasi Basi dan Limbah Buah Pepaya untuk pertumbuhan dan produksi tanaman terong, dengan menuangkanya dalam judul (Pemberian Mol nasi basi dan Mol Limbah Buah Pepaya dengan dosis yang berbeda terhadap Pertumbuhan dan Produksi tanaman terong (Solanum melongena L.)

\section{Metodologi}

Penelitian ini dilaksanakan di Lahan Fakultas Pertanian Universitas Al-Asy'ariah Mandar, Kelurahan Madatte, Kecamatan Polewali, Kabupaten Polewali Mandar. Berlangsung dari bulan Agustus 2018 sampai bulan Oktober 2018. Bahan yang digunakan dalam penelitian ini meliputi benih terong,nasi basi, limbah buah Pepaya, gula merah, air cucian beras, dan polybag. Alat digunakan meliputi meteran, cangkul, skop, parang, cutter steril, ember, sprayer, jergen, baskom, botol aqua, flastisin, sarung tangan, belender, selang, timbangan, kamera dan alat tulis-menulis. Penelitian ini dilaksanakan dengan menggunakan Rancangan Acak. Kelompok (RAK) Penelitian ini terdiri atas 1 faktor dan memperoleh 9 tarap yaitu:

\begin{tabular}{|c|c|}
\hline M0 & $=$ Kontrol (Tanpa Pemberian) \\
\hline M1 & $=$ Pemberian Mol Nasi Basi $20 \mathrm{ml} /$ liter air \\
\hline M2 & $=$ Pemberian Mol limbah pepaya $20 \mathrm{ml} /$ liter air \\
\hline M3 & $=$ Pemberian Mol Nasi Basi 15 ml/liter air \\
\hline M4 & $\begin{array}{l}=\text { Pemberian Mol Limbah Buah Pepaya } 15 \\
\text { ml/liter air }\end{array}$ \\
\hline M5 & $\begin{array}{l}=\text { Pemberian Mol Nasih Basi } 15 \mathrm{ml} / \text { liter air }+ \\
\text { Mol Limbah Buah Pepaya } 15 \mathrm{ml} / \text { liter air }\end{array}$ \\
\hline 16 & $\begin{array}{l}=\text { Pemberian Mol Nasih Basi } 20 \mathrm{ml}+\text { Mol } \\
\text { Limbah Buah Pepaya } 15 \mathrm{ml} / \text { liter air }\end{array}$ \\
\hline M7 & $\begin{array}{l}=\text { Pemberian Mol Nasi Basi } 15 \mathrm{ml}+\text { Mol } \\
\text { Limbah Buah Pepaya } 20 \mathrm{ml} / \text { liter air }\end{array}$ \\
\hline VI & $\begin{array}{l}=\text { Pemberian Mol Nasi Basi } 20 \mathrm{ml}+\text { Mol } \\
\text { Limbah Buah Pepaya } 20 \mathrm{ml} / \text { liter air }\end{array}$ \\
\hline
\end{tabular}
sebanyak 3 (Tiga) kali, sehingga terdapat 18 perlakuan. Setiap Unit penilitian terdapat 2 tanaman sehingga keseluruhan jumlah tanaman 54 tanaman.

\section{Pelaksanaan Penelitian}

Benih

Langkah pertama siapkan dulu tempat persemaian dengan campuran tanah, pupuk kandang dengan 1:1, kemudian rendam benih terong dalam air hangat selama 10-15 menit, setelah itu tabur Di tempat persemain yang sudah di siapkan setelah itu simpan selama 1-2 minggu dan setelah tumbuh bebera helai 1-3 helai daun sudah dapat di pindahkan ke poly beg.

Pembuatan Mikroorganisme Lokal (Mol) Nasi Basi

Adapun alat dan bahan yang digunakan untuk pembuatan pupuk cair mol pepaya yaitu : Jeriken/jerigen, Pisau, Belender, Saringan Alatpengaduk, Ember/bakskom nasi basi $1 \mathrm{~kg}$ Gula merah $200 \mathrm{ml}$, Air cucian beras 1 liter.
Cara pembuatan :

Nasi basi di haluskan dengan meggunakan tangan sesudah itu dimasukan ke wadah dan dicampur dengan gula merah dan air cucian beras. Jika semua langkah diatas telah dilakukan, mol nasi basi diamkan selama 2 minggu, indikasi mol sukses di buat jika tercium aroma wangi seperti permen atau tape. Namun jika mol nasi basih gagal akan tercium bau busuk

Pembuatan Mikroorganisme Lokal ( mol) Limbah buah pepaya

Adapun alat dan bahan yang digunakan untuk pembuatan pupuk cair mol pepaya yaitu :

Botol aqua, Pisau, Belender, Saringan Alat pengaduk, Ember/bakskom, 1 buah pepaya busuk $1 \mathrm{~kg}$, Gula merah $200 \mathrm{ml}$, Air cucian beras 1 liter Cara pembuatan :

a. Potong-potong buah pepaya bebera bagian

b. Setelah itu belender buah pepaya sampai halus masukkan ke dalam ember, sementara iris gula merah tipis-tipis

c. Kemudian aduk dengan air cucian beras ,gula merah dan satukan dengan buah pepaya yang sudah di belender yang tadi dan aduk-aduk hingga merata

d. Sesudah itu masukkan kedalam botol tutup dengan palstisin dengan tujuan agar reaksi pada mol bisa berjalan baik.

Jika semua langkah diatas telah dilakukan, mol buah pepaya busuk diamkan selama 2 minggu, indikasi mol sukses di buat jika tercium aroma wangi seperti permen atau tape. Namun jika mol buah pepaya gagal akan tercium bau busuk.

Persiapan Media Tanam

Pembuatan media tanam untuk tanaman terung ungu yaitupupuk kandang dan tanah dengan perbandingan 1:1 setelah media tanam siap selajutnya dimasukka kedalam poly bag berukuran 40x60 cm kemudian ditata rapi di atas permukaan tanah diolah insentif, kemudiaan di buat parit saluran drainase.

Memindahkan bibit

Memindahkan bibit yang sudah siap ditanam ke polybeg, dengan lubang tanam $2 \mathrm{~cm}$ yang sudah di isi dengan tanah dan pupuk kandang 1:1.

Penyiraman

Pemeliharan dilakukan dengan cara penyiraman sebanyak 1-2 kali sehari (pagi dan sore). disesuaikan dengan keadaan cuaca. Kekurangan air akan mengakibatkan tanaman layu dan menguning. Selain itu dilakukan pada penyiangan. Penyiangan dilakukan apabila ada gulma yang tumbuh di poly beg, perlunya di lakukan agar tidak terjadinya perebutan unsur hara antara tanaman dan gulma kemudian apa bila ada tanaman yang mati sebaiknya dilakukan penyulaman, batas akhir penyulaman dilakukan hingga 4 minggu setelah pemindahan media tanaman dari persemaian ke dalam polybeg.

Penyulaman

Penyulaman dilakukan setidaknya pada umur seminggu atau maksimal 15 hari setelah penanaman, penyulaman dilakukan untuk menyingkirkan tanamaan yang mati, tidak normal, atau yang terserang hama 
penyakit . dan di ganti bibit yang baru.

Pemupukan

Pemupukan dilakukan pada 2 minggu setelah tanamsesuai dengan kombinasi perlakuan.

\section{Hasil}

\section{Tinggi Tanaman}

Sidik ragam menujukkan bahwa pemberian moll limbah buah dengan dosis yang berbeda tidak memberikan pengaruh nyata terhadap parameter tinggi tanaman. Hal ini dapat dilihat pada gambar dibawah :

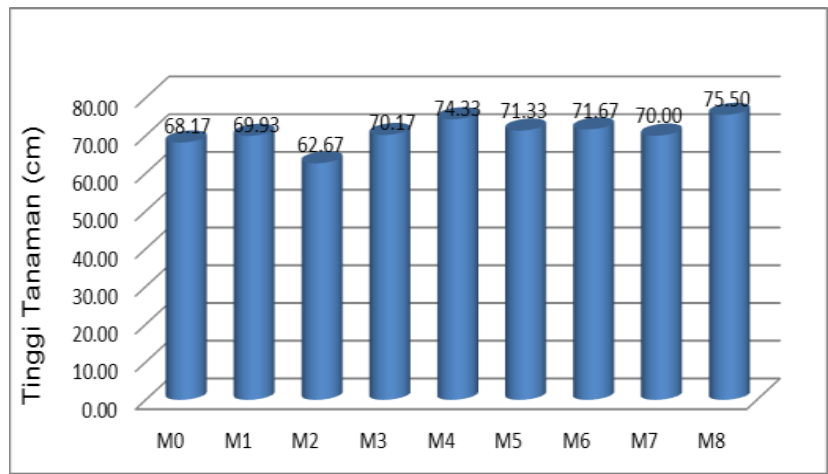

Gambar 1. Diagram Batang Tinggi Tanaman pada MolLimbah Buah Pepaya dengan Dosis Berbeda Terhadap Pertumbuhan dan Produksi Tanaman Terong

Berdasarkan gambar 1. Menunjukkan bahwa pemberian Mol limbah Buah Pepaya dengan Dosis 40 $\mathrm{ml} /$ liter air (M8), memiliki tinggi tanaman tertinggi dengan nilai $75.50 \mathrm{~cm}$ dibandingkan dengan perlakuan lain.

\section{Diameter Batang}

Sidik ragam menujukkan bahwa pemberian Mol Nasi Basi dan mol Limbah Buah Pepaya dengan dosis yang berbeda tidak memberikan pengaruh nyata diameter batang terhadap tanaman. Hal ini dapat dilihat pada gambar dibawah :

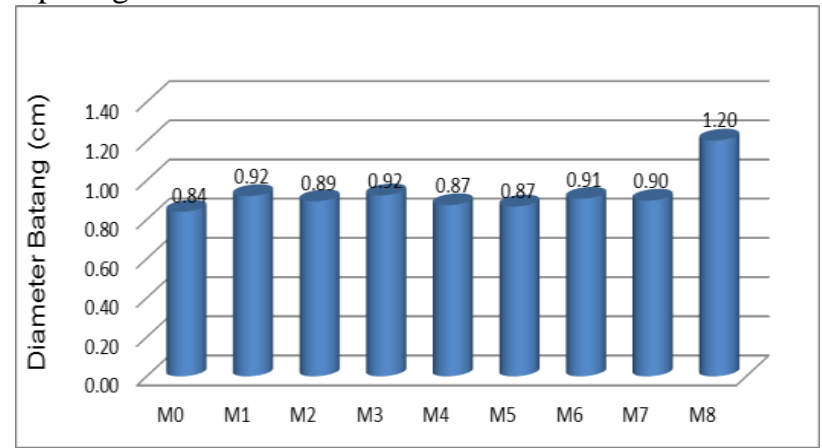

Gambar 1. Diagram Batang Tinggi Tanaman pada Mol Limbah Buah Pepaya dengan Dosis Berbeda Terhadap Pertumbuhan dan Produksi Tanaman Terong

Berdasarkan gambar 1. Menunjukkan bahwa pemberian Mol limbah Buah Pepaya dengan Dosis 40 $\mathrm{ml} /$ liter air (M8), memiliki tinggi tanaman tertinggi dengan nilai $75.50 \mathrm{~cm}$ dibandingkan dengan perlakuan lain.

\section{Jumlah daun}

Sidik ragamnya menujukkan bahwa pemberian Mol Nasi Basi dan Mol Limbah Buah Pepaya memberikkan pengaruh nyata.

Tabel 1. Rata-rata jumlah daun (helai) pada pemberian Mol Nasi Basi dan Limbah Buah Pepaya dengan dosis yang berbeda terhadap pertumbuhan dan produksi tanaman terong

\begin{tabular}{lll}
\hline Pemberian mol (ml/literair) & Rata-Rata & $\begin{array}{l}\text { BNT Taraf } \boldsymbol{\alpha} \\
\mathbf{0 , 0 5}\end{array}$ \\
\hline (M0) Control & $24.83^{\mathrm{a}}$ & 8.68 \\
(M1) Nasi basi 20 & $26.00^{\mathrm{a}}$ & \\
(M2) Limbah buah pepaya 20 & $23.67^{\mathrm{a}}$ & \\
(M3) Nasi basi 15 & $27.50^{\mathrm{a}}$ \\
(M4) Limbah buah pepaya15 & $35.17^{\mathrm{a}}$ \\
$\begin{array}{l}\text { (M5) Nasi basi 15 + limbah } \\
\text { pepaya 15 }\end{array}$ & $32.17^{\mathrm{a}}$ \\
$\begin{array}{l}\text { (M6) Nasi basi 20 + limbah } \\
\text { pepaya 15 } \\
\text { (M7) Nasi basi 15 + limbah }\end{array}$ & $31.50^{\mathrm{a}}$ \\
$\begin{array}{l}\text { pepaya 20 } \\
\text { (M8) Nasi basi 20 + limbah } \\
\text { pepaya 20 }\end{array}$ & $29.50^{\mathrm{ab}}$ \\
\hline
\end{tabular}

Keterangan : Angka-angka yang di ikuti oleh huruf yang tidak sama berarti berbeda nyata pada UJBD Taraf $\alpha 0,05$ pada Tabel

Hasil Uji Berbeda Nyata Terkecil (BNT) pada Taraf $\alpha 0,05$ pada Tabel1. Memperlihatkan bahwa perlakuan (M8) memberikan pengaruh baik dan berbeda nyata dengan perlakuan (M7) dan Tidak berpengaruh nyata dengan perlakuan lain.

\section{Jumlah buah}

Data pengamatan jumlah daun dan sidik ragam disajikan pada tabel lampiran 4a dan 4b. sidik ragamnya menujukkan bahwa pemberian Mol Nasi Basi dan Mol Limbah Buah Pepaya memberikkan pengaruh nyata. 
Tabel 2. Rata-Rata Jumlah Buah Pada Pemberian Mol Nasi Basi dan Mol Limbah Buah Pepaya dengan Dosis yang Berbeda Terhadap Pertumbuhan dan Produksi TanamanTerong

\begin{tabular}{lll}
\hline \multicolumn{1}{c}{$\begin{array}{c}\text { Pemberian mol } \\
\text { (ml/liter air) }\end{array}$} & $\begin{array}{c}\text { Rata- } \\
\text { Rata }\end{array}$ & $\begin{array}{c}\text { BNT } \\
\text { Taraf } \boldsymbol{\alpha}\end{array}$ \\
\hline (M0) Control & $5.33^{\mathrm{a}}$ & 1.78 \\
\hline (M1) Nasi basi 20 & $6.50^{\mathrm{a}}$ & \\
\hline (M2) Limbah buahpepaya 20 & $5.67^{\mathrm{a}}$ \\
\hline (M3) Nasi basi 15 & $5.50^{\mathrm{a}}$ \\
\hline $\begin{array}{l}\text { (M4) Limbah buah } \\
\text { pepaya15 }\end{array}$ & $6.83^{\mathrm{a}}$ \\
\hline $\begin{array}{l}\text { (M5) Nasi basi 15 + } \\
\text { limbah pepaya 15 }\end{array}$ & $7.00^{\mathrm{a}}$ \\
\hline $\begin{array}{l}\text { (M6) Nasi basi 20 + } \\
\text { limbah pepaya 15 }\end{array}$ & $7.33^{\mathrm{a}}$ \\
\hline $\begin{array}{l}\text { (M7) Nasi basi 15 + } \\
\text { limbah pepaya 20 }\end{array}$ & $6.67^{\mathrm{a}}$ \\
\hline $\begin{array}{l}\text { (M8) Nasi basi 20 + } \\
\text { limbah pepaya 20 }\end{array}$ & $8.83^{\mathrm{b}}$ \\
\hline $\begin{array}{l}\text { Keterangan : Angka-angka yang di ikuti oleh huruf yang tidak } \\
\text { sama berarti berbeda nyata pada UJBD Taraf } \alpha \\
0,05\end{array}$
\end{tabular}

Hasil Uji Berbeda Nyata Terkecil padaTaraf $\alpha 0,01$ pada Tabel 2. Memperlihatkan bahwa perlakuan (M8) berpengaruh lebih baik dan tidak berbeda nyata dibandingkan dengan perlakuan yang lain.

Bobot Basah Buah

Data pengamatan jumlah bobot basah buah dan sidik ragam disajikan pada tabel lampiran 5a dan 5b. sidik ragamnya menujukkan bahwa pemberian Mol Nasi Basi dan Limbah Buah Pepaya memberikkan pengaruh nyata.

Tabel 3. Rata-rata jumlah bobot basah buah pada pemberian Mol Nasi Basi dan Limbah Buah Pepaya dengan dosis yang berbeda terhadap pertumbuhan dan produksi tanaman terong

\begin{tabular}{|c|c|c|}
\hline $\begin{array}{l}\text { Pemberian mol } \\
\text { (ml/liter air) }\end{array}$ & Rata-Rata & $\begin{array}{l}\text { BNT Taraf } \\
\alpha 0,01\end{array}$ \\
\hline (M0) Control & $182.41^{\mathrm{a}}$ & 63.49 \\
\hline (M1) Nasi basi 20 & $230.88^{a}$ & \\
\hline $\begin{array}{l}\text { (M2) Limbah buah } \\
\text { pepaya } 20\end{array}$ & $177.03^{\mathrm{a}}$ & \\
\hline (M3) Nasi basi 15 & $190.62^{\mathrm{a}}$ & \\
\hline $\begin{array}{l}\text { (M4) Limbah buah } \\
\text { pepaya15 }\end{array}$ & $250.40^{\mathrm{a}}$ & \\
\hline $\begin{array}{l}\text { (M5) Nasi basi } 15+ \\
\text { limbah pepaya } 15\end{array}$ & $250.25^{\mathrm{ax}}$ & \\
\hline $\begin{array}{l}\text { (M6) Nasi basi } 20+ \\
\text { limbah pepaya } 15\end{array}$ & $247.58^{\mathrm{ax}}$ & \\
\hline $\begin{array}{l}\text { (M7) Nasi basi } 15+ \\
\text { limbah pepaya } 20\end{array}$ & $218.05^{\mathrm{ax}}$ & \\
\hline $\begin{array}{l}\text { (M8) Nasi basi } 20+ \\
\text { limbah pepaya } 20\end{array}$ & $322.03^{b}$ & \\
\hline
\end{tabular}

Hasil Uji Berbeda Nyata Terkecil pada Taraf $\alpha$ 0,01 pada Tabel 3. Memperlihatkan bahwa perlakuan (M8) berpengaruh lebih baik dan berbeda nyata dengan $(\mathrm{M} 5, \mathrm{M} 6, \mathrm{M} 7)$ namun tidak berbeda nyata (M0,M1,M2,M3,M4).

\section{Pembahasan \\ Tinggi Tanaman}

Tinggi tanaman merupakan ukuran yang diamati dalam fase pertumbuhan vegetatif tanaman, padagambar 1 diagram batang rata-rata tinggi tanaman menujukkan bahwa pemberian Mol Nasi Basi dan Mol Limbah Pepaya dengan dosis $20 \mathrm{ml} /$ liter air memberikan hasil tinggi tanaman tertinggi yaitu $75,50 \mathrm{~cm}$, hal ini diduga karena mikroba-mikroba dari Mol yang diberikan mampu mendegradasi bahan-bahan organik, sehingga dapat $d$ iserap dengan baik dalam membantu proses metabolisme pada tanaman baik dalam menyerap unsur hara dan mentranslokasikan energi atau karbohidrat yang dimilikinya, menurut Basir N, M, et.al., (2017) Unsur hara tambah yang didapatkan dari penggunaan pupuk organik cair ini membuat aktifitas metabolisme pada tanaman menjadi aktif, Unsur hara menjadi syarat utama dalam fotosintesi, ketika tanaman berfotosintesi maka hasil dari fotosintesis, ini berupa energi (karbohidrat) untuk tanaman kemudian ditranslokasikan ke seluruh bagian organ tanaman. Pertumbuhan vegetative tanaman menjadi lebih optimal ketika median tanaman yang digunakan memiliki struktur tanah yang baik, dalam hal ini system perakaran pada tanaman lebih luas untuk berkembang, ketika perakaran tanaman menjadi besar maka dalam penyerapan Unsur Hara yang berada dalam tanah juga diserap lebih banyak.

\section{Diameter Batang}

Pengukuran diameter batang dilakukan untuk mengetahui proses perkembangan batang dengan pertumbuhan tanaman,pengukuran diameter batang dilakukan pada batang utama. dari hasil pengamatan berdasarkan diagram batang menujukkan nilai tertinggi tanaman $1,20 \mathrm{~cm}$ memberikan diameter batang terbesar, hal ini diduga pertumbuhan diameter batang tanaman terong pertumbuhan tinggi tanaman, dikarenakan proses dalam proses translokasi unsur hara dalam tanah menuju bagian daun melalui batang yang diangkat oleh jaringan xylem dan flom. Jaringan xylem mempunyai fungsi sebagai jaringan mengakut unsur hara yang di peroleh dari dalam tanah seperti $\mathrm{H}_{2} \mathrm{O}, \mathrm{N}, \mathrm{P}$ dan unsur hara lainnya, sedangkan jaringan floem mengankut hasil fotosintesis diangkut hasi fotosintesis yang berupa fotosintat seperti sukrosa, asam amino, menurut Lakitan (2015) menyatakan bahwa telah diketahui sejak lama bahwa hasil fotosintesis diangkut dari daun ke organ lain seperti, akar, batang, dan organ produktif melalui pembuluh floem. Proses pengangkutan ini terjadi melalui batang sehingga diameter batang akan terus meningkat untuk memperlancar dalam proses pengangkutan fotosintat dan unsur hara. 


\section{Jumlah Daun}

Pertumbuhan daun merupakan bagian dari pertumbuhan vegetatif tanaman. pertumbuhan vegetatif unsur yang paling banyak dibutuhkan adalah nitrogen, hal ini diduga bahwa pemberian berbagai dosis pupuk organik menghasilkan jumlah daun tanaman terong yang lebih banyak dibandingkan dengan tanpa pupuk an organik. Hal ini disebabkan karena tanaman terong tumbuh dengan pesat dan membutuhkan unsur hara terutama $\mathrm{N}$, sehingga dengan pemberian pupuk organik dapat meningkatkan ketersediaan unsur $\mathrm{N}$ tersebut.Seperti dikemukakan oleh Wijaya (2008) bahwa unsur hara yang paling berpengaruh terhadap pertumbuhan dan perkembangan daun adalah unsur $\mathrm{N}$, kadar unsur $\mathrm{N}$ yang banyak umumnya menghasilkan daun yang lebih banyak dan lebih besar.

\section{Jumlah Buah}

Berdasarkan hasil penilitian jumlah buah terong menujukkan bahwa pemberian Mol Nasi Basi dan Mol Limbah Buah Pepaya dengan dosis $40 \mathrm{ml} /$ liter memiliki nilai tertinggi dalam jumlah buah, yaitu 8,83 Hal ini dikarenakan Mol Nasi Basi banyak mengandung mikroba yang bisa membantuh decomposer untuk ketersedian unsur hara yang di peroleh agar bisa diserapoleh tanaman dan mampu untuk meningkatkan buah. pada pembentukan bunga dan buah, hara didapatkan cukup dan tersedia untuk proses pembentukan tanaman dalam hal ini jumlah buah, semakin besar ukuran tanaman dan sistem perakaran yang dimiliki ini baik, maka semakinbesar pula diameter buah yang akan berbentuk, hal ini juga sejalan dengan jumlah buah yang terbentuk semakin banyak, menurut Armaini et.al.,(2011).

\section{Bobot Basah Buah}

Bobot basah buah merupakan bobot tanaman yang tidak mengalami proses pengeringan terlebih dahulu. Pada prameter bobot basah buah penggunaan pupuk organic cair pepaya dengan dosis $40 \mathrm{ml} / \mathrm{liter}$ air memberikan bobot basah terbesar hal ini diduga buah pepaya mengandung karbohidrat, kalsium, mangnesium, dan fosfor yang tinggi sehingga mampu untuk mendapatkan dan meningkatkan berat buah(Nisa,2016), dan Penggunaan pupuk organik cair memiliki keunggulan yakni walaupun sering digunakan tidak merusak tanah dan tanaman, pemanfaatan limbah organik sebagai pupuk dapat membantu memperbaiki struktur dan kualitas tanah, karena memiliki kandungan unsur hara (NPK) dan bahan organik lainnya (Hadisuwito, 2007).

\section{Kesimpulan}

Pemberian Mol Nasi Basi 20 ml/liter air dan Limbah Buah Pepaya dengan $20 \mathrm{ml} /$ liter air memberikan pengaruh baik pada jumlah daun, jumlah buah dan berat buah.

\section{Daftar Pustaka}

Armaini, Wardati, dan Zulfatr. 2011. Serapan N, P, K, dan produksi jagung (Zea mays) pada tanah gambut bekas dengan pemberian Tithonia diversifolia sebagai bahan ameliorant. Jurnal SAGU10 (1):8-13.
Azhar, M.A.,I.Bahua,danF.S. Jamin. 2013.Pengaruh Pemberian Pupuk NPK Pelangi terhadap Pertumbuhan dan Produksi Tanaman Terung (Solanummelongena L.). Bone Bolango. http://info/46653243- Pengaruh-pemberian-pupuk-npkpelangiterhadap-pertumbuhan-danproduksi- tanaman-terung-solanum melongena-1.html(Diakses pada 19 November 2016).

Basir Nappu Muhammad, Herniwati dan Syukur Syarief Abdul.2013. Pemanfaatan Limbah Kakao menjadi Pupuk Organik dengan MenggunakanBioaktivator Mikroorganisme Lokal (MOL) Buah Pepaya pada tanaman Kakao Produktif. Balai Pengkajian Teknolagi Pertanian Sulawesi Selatan. Makassar.

Data Kemeterian Pertanian Republik Indonesia Produksi tanaman terong (2017).

Doni Sriyanto dkk,. 2015. Pengaruh Dosis Pupuk Kandang Sapi Terhadap Pertumbuhan Dan Hasil Tanaman Terung Ungu Dan Terung Hijau (Solanum melongena $L$.).jurnal AGRIFORVolume XIV Nomor 1 Maret 2015. ISSN. 1412 6885 .

Firmanto, B. 2011.Sukses bertanaman terung secara organik. Angkasa, Bandung. Diakses 24 Agustus 2016.

Hadisuwito. 2007.Membuat Kompos Cair. Jakarta:PT Agromedia Pustaka.

Handayani Sri Hesti,dkk,. 2015. Uji kualitas pupuk organic cair dari berbagai macammikroorganisme local (MOL). EL- VIVO, Vol.3, No.1; 54-60

Ismaya NR Parawansa dkk,. 2014 .Mikroorganisme Lokal (Mol) Buah Pisang Dan Pepaya Terhadap Pertumbuhan Tanaman Ubi Jalar (Ipomea batatasL) Jurnal Agrisistem,Vol. 10 No.1 ISSN 18584330

Jumini dan Ainun Marliah. 2009.Fakultas Pertanian Unsyiah, J. Floraktek4:73-80 pdf dakses 19 Nov 2014 16. Pertumbuhan Dan Hasil Tanaman Terung Akibat Pemberian Pupuk Daun Gandasil D Dan Zat Pengatur Tumbuh armoni.

Joko Prianto, Yogyakarta, Agustus 2016 Cara Gampang Usaha Dan Bisnis Terong.

Lakitan Benyamin, 2015. Dasar - Dasar Fisiologi Tanaman. Rajawali Pres. Jakarta

Musnawar. 2007.Petunjuk Penggunaan PupukKalsium dan Magnesium. PenebarSwadaya. Jakarta.

Nisa Khalimatu.2016.Memproduksi Kompos dan Mikro Organisme Lokal (MOL). Jakarta:BibitPublisher.

Pracaya. 2002. Bertanam Sayur Organik di Kebun, Pot dan Polybag. Jakarta: Penebar Swadaya.212 hal

Pranata.AS. 2004. Pupuk Organik Cair. AgromediaPustaka. Jakarta

Rukmana, R. 2013. Bertanam terung. Kanasius, Jogyakarta.

Sarmi julita dkk,.2013 Pengaruh Pemberian mikroorganisme Lokal (Mol) Nasi dan Hormon Tanaman Unggul terhadap Pertumbuhan dan Produksi Tanama Cabai (Capsicum Annum L.) Jurnal Dinamika Pertania Volume 3 (167. 174) ISSN 0215-2525.

Setianingsih, R. 2009. Kajian Pemanfaatan Pupuk Organik Cair Mikro Organisme Lokal (MOL) dalam Priming, Umur Bibit dan Peningkatan Daya Hasil Tanaman Padi (Oryza sativa L.) .Uji Coba penerapan Systemof Rice Intensification (SRI).Balai Pengawasan dan Sertifikasi Benih Tanaman.Pangan (BPSB) Propinsi Daerah Istimewa Yogyakarta. Hal 12-14.

Simatupang, A.2010.Pengaruh beberapa jenis pupuk organiak terhadap Pertumbuhan dan hasil tanaman terung (Soanum Melongena L.)Skripsi Fakultas pertanianUniversitasAndalas. Padang.230 hlm

Sufianto. 2014. Analisis mikroba pada cairan sebagaipupuk cair limbah organik dan aplikasinya terhadap tanaman pakcoy (Brassica chinensis L.) Jurnal Gamma 9 (2): 77-94.

Wijaya K.A.2008 Nutris iTanaman. Prestasi Pustaka. Jakarta. 115 halaman 